\title{
Spared Discrimination and Impaired Reversal Eyeblink Conditioning in Patients with Temporal Lobe Amnesia
}

\section{Citation}

Carrillo, M. C., J. D. E. Gabrieli, R. O. Hopkins, R. McGlinchey-Berroth, C. B. Fortier, R. P. Kesner, and J. F. Disterhoft. 2001. Spared Discrimination and Impaired Reversal Eyeblink Conditioning in Patients With Temporal Lobe Amnesia." Behavioral Neuroscience 115, no. 6: 1171-179.

\section{Published Version}

10.1037/0735-7044.115.6.1171

\section{Permanent link}

http://nrs.harvard.edu/urn-3:HUL.InstRepos:42643043

\section{Terms of Use}

This article was downloaded from Harvard University's DASH repository, and is made available under the terms and conditions applicable to Open Access Policy Articles, as set forth at http:// nrs.harvard.edu/urn-3:HUL.InstRepos:dash.current.terms-of-use\#OAP

\section{Share Your Story}

The Harvard community has made this article openly available.

Please share how this access benefits you. Submit a story.

\section{Accessibility}




\section{Spared Discrimination and Impaired Reversal Eyeblink Conditioning in}

\section{Patients with Temporal Lobe Amnesia}

M.C. Carrillo1, J.D.E. Gabrieli1,2, R.O. Hopkins3, R. McGlinchey-Berroth4,5, C. B. Fortier5, R. P. Kesner6, \& J.F. Disterhoft7

1Dept. of Neurological Sciences, Rush-Presbyterian-St. Luke's Medical Center, Chicago, IL 60612

2Dept. of Psychology, Stanford University, Stanford, CA 94305

3 Depts. of Psychology and Neuroscience, Brigham Young University, Provo, UT 84143

4 Geriatric Research, Education, \& Clinical Center, VA Boston Healthcare System, and the Dept. of Psychiatry, Harvard University, Boston, MA 02132

5 Memory Disorders Research Center, Boston University School of Medicine, Boston, MA 02132

6 Dept. of Psychology, University of Utah, SLC, UT 84112

7 Dept. Cell and Molecular Biology, Northwestern University, Chicago, IL 60611

Running Head: DISCRIMINATION AND REVERSAL IN AMNESIA

Correspondence to: $\quad$ Maria C. Carrillo, Ph.D.

Dept. Neurological Sciences, Cog. Neuroscience Section

Rush-Presbyterian-St. Luke's Medical Center

1645 W. Jackson Blvd. Suite 450

Chicago, IL 60612

Telephone: (312) 432-5027

Fax: $\quad$ (312) $432-9332$

email: mcarrill@rush.edu 
ACKNOWLEDGEMENTS: Supported by F31 GM 17223 to MCC, NINDS 1P50NS26985, NIH R01 AG08796 \& NIH MH 47340 to JFD. 
ABSTRACT

The effect of medial temporal lobe damage on a two tone delay discrimination and reversal paradigm was examined in human classical eyeblink conditioning. Eight medial temporal lobe amnesics and their demographically matched controls were compared. Amnesics were able to distinguish between two tones during the initial discrimination phase of the experiment almost as well as control participants. Amnesic patients were not able to reverse the previously acquired two tone discrimination. In contrast, the control participants showed improved discrimination performance after the reversal of the tones. These findings support the hypothesis that the hippocampus, and associated temporal lobe regions, play a role in eyeblink conditioning that becomes essential in more complex versions of the task, such as the reversal of an acquired two tone discrimination. 


\section{INTRODUCTION}

Classical eyeblink conditioning has been a widely used associative learning paradigm in both animals and humans. It is one of few learning models that has been well characterized behaviorally (Gormezano, Kehoe, \& Marshall, 1983) and can be used in both animals and humans with essentially the same procedures and parameters. Eyeblink conditioning involves the acquisition of a conditioned response dependent on the repeated presentation of previously neutral paired stimuli, such as a tone conditioned stimulus (CS) followed by an airpuff to the eye as an unconditioned stimulus (US).

Animal studies have delineated the neural circuitry underlying the eyeblink associative task (Thompson, 1986, 1988). These studies have shown that the CS-US association involves the cerebellum, ipsilateral to the eye receiving the airpuff, and that lesions of the cerebellar dentate-interpositus nuclei prevent acquisition or abolish retention of the ipsilateral conditioned response (Clark, McCormick, Lavond, \& Thompson, 1984; Green \& Woodruff-Pak, 2000; Lavond, Hembree, \& Thompson, 1985; Lavond, Lincoln, McCormick, \& Thompson, 1984; Lincoln, McCormick, \& Thompson, 1982; McCormick \& Thompson, 1984a \& 1984b; Yeo, Hardiman \& Glickstein, 1985). Several studies in humans have now shown impaired acquisition of classical eyeblink conditioning in patients with cerebellar lesions (Daum, Schugens, Ackermann, Lutzenberger, Dichgan, \& Dirbaumer, 1993; Lye, O-Boyle, Ramsden, \& Schady, 1988; 
Solomon, Stowe, \& Pendlebury, 1989; Woodruff-Pak, Papka, \& Ivry, 1996) and cerebellar degeneration (Fortier, Disterhoft, \& McGlinchey, 2000; McGlinchey-Berroth, Cermak, Carrillo, Armfiled, Gabrieli, \& Disterhoft, 1995; Topka, Valls-Sole, Massaquoi, \& Hallet, 1992; Woodruff-Pak et al., 1996).

The hippocampus is known to be engaged during the development of the conditioned response. Electrophysiological studies have shown conditioning specific changes in pyramidal cells of the CA1 region of the rabbit hippocampus that correlate with development of the conditioned response (Berger, Rinaldi, Weisz, \& Thompson, 1983; Berger \& Thompson, 1978; Berger \& Weisz, 1987; Disterhoft, Coulter, \& Alkon, 1986; McEchron \& Disterhoft, 1997, 1999; Weiss, Kronforst-Collins, \& Disterhoft, 1996). Imaging studies in humans have also shown hippocampal activation during the acquisition of the conditioned response (Blaxton, Zeffiro, Gabrieli, Bookheimer, Carrillo, Theodore, \& Disterhoft, 1996; Buchel, Dolan, Armony, \& Friston, 1999; Logan \& Grafton, 1995).

Evidence of hippocampal involvement in eyeblink conditioning indicates that the hippocampus is essential only for acquisition of more complex versions of the task. For example, the delay conditioning task, the most simple paradigm in which the tone (CS) and airpuff (US) overlap and coterminate, does not require the hippocampus in either animals (Akase, Alkon, \& Disterhoft, 1989; Berger \& Orr, 1983; Schmaltz \& Theios, 1972; Solomon \& Moore, 1975) or humans (Daum, Channon, \& Canavan, 1989; Gabrieli, 
McGlinchey-Berroth, Carrillo, Gluck, Cermak, \& Disterhoft, 1995). The trace conditioning paradigm, however, places additional demands on the subject by introducing a silent interval between the tone (CS) and airpuff (US). This temporal demand engages forebrain structures, in addition to brainstem and cerebellum. Rabbits, rats, and humans with hippocampal lesions or medial temporal lobe damage are impaired in trace eyeblink conditioning (McGlinchey-Berroth, Carrillo, Brawn, Gabrieli, Cermak, \& Disterhoft, 1997; Moyer, Deyo, \& Disterhoft, 1990; Solomon, Vander Schaaf, Thompson, \& Weisz, 1986; Weiss, Bouwmeester, Power, \& Disterhoft, 1999). These results suggest that the hippocampus may be required when two stimuli are temporally dissociated such as occurs in trace conditioning.

Discrimination, a more complex version of eyeblink classical conditioning, involves the presentation of two conditioned stimuli, one of which (the CS+) is paired with the airpuff unconditioned stimulus (US), while the other stimulus (CS-) is presented alone. During reversal conditioning, the significance associated with the two previously presented tones is reversed by making the previously unpaired tone (CS-) the $\mathrm{CS}_{+}$, and the previously paired tone (CS+) now the CS-. Delay or trace discrimination procedures can be used, depending on the duration and termination of the tone (CS) in relation to the airpuff (US).

Berger and Orr showed that rabbits with hippocampal lesions can acquire a twotone discrimination (Berger \& Orr, 1983; Orr \& Berger, 1985), but are unable to 
successfully reverse. The reversal failure does not reflect a discrimination deficit, as they are able to make the initial discrimination. The rabbits are unable to prevent conditioned responses to the new CS- (old CS+), responding to both the CS + and CS(Orr \& Berger, 1985). Electrophysiological evidence indicates that the hippocampus may play an important role in reversal. Miller and Steinmetz (1997) described learning related hippocampal multi-unit activity during initial acquisition of two tone delay discrimination. They also reported no conditioned response related activity during the early phase of the reversal, when the rabbits were exhibiting conditioned responses to both the new CS+ (old CS-) and new CS- (old CS+), and that characteristic learningrelated hippocampal activity resumed when the rabbits began to discriminate after reversal. These results indicate that the hippocampus is active during conditioned response learning and essential in its reversal.

Discrimination conditioning has been examined in humans with lesions. Patients with unilateral left or right medial temporal lobe resections successfully acquired a simple two-tone discrimination (Daum, Channon, \& Gray, 1992), but not a more complex conditional discrimination task in which the color of a light CS presented before a tone signified whether the trial would be reinforced with an airpuff or not (CSCS-US) (Daum, Channon, Polkey, \& Gray, 1991). Patients with bilateral temporal lobe damage were also unable to acquire or reverse a complex conditional discrimination (Daum et al., 1989). McGlinchey-Berroth, Brawn, and Disterhoft (1999) reported a 
deficit in amnesic patients' performance on a temporal discrimination task in which two tone CSs signal two different interstimulus intervals before US (airpuff) onset. They conclude that an intact hippocampal system is required to control the precise timing of conditioned eyeblink responses. Clark and Squire (1998) examined the role of awareness (conscious knowledge) of CS-US stimulus contingencies in delay and trace discrimination learning and found that amnesic patients were able to acquire delay twocue discrimination, but were impaired in a trace discrimination, in spite of not being aware of the CS-US contingency in either situation. These results are consistent with amnesic patients being intact for delay but impaired for trace single-cue conditioning, (Gabrieli et al., 1995; McGlinchey-Berroth et al., 1997) as well as with animal reports in which rabbits with hippocampal lesions were able to acquire a delay two tone discrimination (Berger \& Orr, 1983; Orr \& Berger, 1985).

The previous studies have indicated that the hippocampus is not required to acquire delay two-tone discrimination in animals or humans. However, the ability to reverse a simple two-tone delay discrimination in humans with medial temporal lobe damage remains unclear. In the present study, we investigated the role of the hippocampus in delay discrimination and reversal in eight patients with medial temporal lobe damage and eight healthy control participants. The delay discrimination paradigm involved two tones, a CS+ (paired with US) and a CS- (unpaired tone). The CS+ tone overlapped and coterminated with the airpuff US, in a delay conditioning design. 
During discrimination reversal, the significance of the tones was reversed and the airpuff (US) was paired with the previously unreinforced CS. Based on previous studies in animals and humans, we predicted that humans with medial temporal lobe damage would be able to make an initial two tone discrimination, but be unable to reverse this discrimination.

\section{METHOD}

Amnesic Participants Amnesic participants in this study were recruited from the Division of Pulmonary and Critical Care Medicine at LDS Hospital in Salt Lake City, Utah and from the Memory Disorders Research Center at the VA Healthcare System, Boston, MA. Eight amnesic patients participated in this study, four female and four male. Seven patients became amnesic as a result of an anoxic episode ( 1 drug overdose, 2 seizure, 4 cardiac arrest) and 1 patient as a result of encephalitis. These etiologies resulted in decreased blood flow and/or oxygen supply to the brain resulting in medial temporal lobe damage. Blilateral damage to the hippocampal formation was confirmed by computerized tomography $(\mathrm{CT})$ in three cases and magnetic resonance imaging (MRI) in five cases. In all patients bilateral hippocampal damage was confirmed in radiological reports. No evidence of cerebellar damage was found in the neurological examination. The encephalitis patient had extensive bilateral medial temporal lobe damage including the hippocampus. This patient had additional left peri-ventricular white matter damage 
due to a shunt. The MRI for this patient (patient SS) can be viewed in a recently published report by Verfaellie, Koseff, \& Alexander (2000). No other cortical damage or structural lesions were found in the anoxic patients. In addition, hippocampal atrophy was confirmed in two anoxic patients without perirhinal or entorhinal cortical damage by quantitative volumetric MRI. An MRI of one anoxic patient and a matched control participant can be seen in Figure 1 (Kesner \& Hopkins, 2001; Myers, Hopkins, Kesner, Monti \& Gluck, 2000). Although it appears there is selective hippocampal damage in our hypoxic subjects, there may be more diffuse damage which is not so easily assessed but which may nonetheless impact performance. Cerebellar damage seems unlikely as confirmed by the radiology reports and neurological examinations. Further, in this report all eight amnesic patients successfully acquired delay eyeblink discrimination as well as controls (see below). Performance on this task would have been impaired in patients with cerebellar lesions (Fortier et al., 2000; Green \& Woodruff-Pak, 2000).

Demographic and neuropsychological characteristics of the amnesic participants are presented in Table 1. All patients were severely memory impaired as evidenced by their poor recall performance on the delay portion $(M=62.25, S E=3.9)$ of the Wechsler Memory Scale-Revised (WMS-R: Wechsler, 1987). The amnesic patients had preserved intellectual and attentional function, however, as indicated by their verbal score performance $(M=105.5 S E=3.7)$ on the Wechsler Adult Intelligence Scale-Revised (WAIS-R, Wechsler, 1981) and their WMS-R attention score $(M=98.5, S E=3.5)$. In 
addition, all participants underwent complete neurological exams which were all normal with the exception of the memory component.

Control Participants Eight control participants were recruited from the Memory Disorders Research Center in Boston, MA and the Northwestern University Medical School communities. The control group was matched to the amnesic group with regard to age (Control $M=48.1, S E=5.4 ;$ Amnesic $M=50.2, S E=4.7 ; \mathrm{t}(14)=-0.3, p>.05)$, gender, and years of education (Control $M=14.8, S E=0.7$; Amnesic $M=15.7, S E=1.0$; $\mathrm{t}(14)=-0.8, p>.05)$

Apparatus The apparatus used was a modified version of that previously used for rabbit and human eyeblink conditioning and extensively described elsewhere (Akase, Thompson, \& Disterhoft, 1994; Carrillo, Thompson, Gabrieli, \& Disterhoft, 1997; Gabrieli et al., 1995; McGlinchey-Berroth et al., 1997; Thompson, Moyer, Akase, \& Disterhoft, 1994).

Discrimination and discrimination reversal involved a delay configuration with 1 and $5 \mathrm{kHz}$ tones as the CS+ and CS- presented at $85 \mathrm{~dB}$. The tone CSs were $700-\mathrm{msec}$ in duration, had a 5 msec rise/fall time, were delivered binaurally with headphones, and the tone designated as the CS+ coterminated with a $100-\mathrm{msec} 3$ psi corneal airpuff unconditioned stimulus (US) to the right eye. CS tone frequencies were 
counterbalanced among all participants. The computer monitored eyeblinks for a baseline period of 750-msec prior to the onset of the CS. In total, eyeblinks were monitored for 2000-msec per trial. The intertrial interval was 8 to 12 -sec with an average of $10-\mathrm{sec}$. This interval has been shown to support robust acquisition of the conditioned response by Carrillo et al., (1997) and has been used in several reports of classical eyeblink conditioning (Carrillo, Gabrieli, \& Disterhoft, 2000; Knuttinen, Power, Preston, \& Disterhoft, 2001; McGlinchey et al., 1997; McGlinchey et al., 1999). A slightly longer (10 to $15 \mathrm{sec}$ ) ITI has been used by Squire and colleagues in their eyeblink conditioning experiments (Clark \& Squire, 1998; Manns, Clark, \& Squire, 2000).

Eyeblink responses were measured with an infrared diode/photo transistor aimed at the right eye (Thompson et al., 1994). This device monitors and amplifies light reflectance from the cornea in a 0-5 VDC range, which is then digitized and stored by the computer. In this system, eyeblink amplitude is an inverse function of the amount of reflected light contacting the phototransistor aimed at the cornea. The detector was adjusted so that the baseline or null setting was near $1 \mathrm{~V}$ when the eye was open and at the highest amplitude possible (less than $5 \mathrm{~V}$ ) when the eye was fully closed. The detector and the airpuff delivery nozzle were attached to an adjustable headband along with an airpuff delivery nozzle. Stimuli were delivered and responses analyzed by an IBM-AT compatible microcomputer (Akase et al., 1994). 
An eyeblink was scored as a conditioned response (CR) if it was three standard deviations greater than the mean baseline response amplitude. Eyeblinks with a latency of less than $100 \mathrm{~ms}$ after CS onset were recorded as alpha responses and were not considered CRs (Gormezano, 1966). Additionally, the number of spontaneous blinks was tabulated. These were responses for which there was a partial or complete closing of the eyelid during the baseline period before the onset of the CS.

Procedure Participants were seated and asked to sign an informed consent statement. Each participant underwent an audiogram with a Beltone Model 119 audiometer at five frequencies: 500, 1000, 2000, 4000 and $6000 \mathrm{~Hz}$. All participants were no more than $20 \mathrm{~dB}$ above normal hearing range ( $25 \mathrm{db}$ re .0009 newtons/cm2, ANSI Standards, 1973) at these test frequencies, and no adjustments were necessary for hearing impairment.

Participants were seated in a darkened room and told to fixate on a blank television screen in front of them. The experimenter fitted each participant with the eyeblink apparatus, and read the following instructions:

Please make yourself comfortable and look straight ahead. You will experience different stimuli from time to time including some tones through the headphones and a mild puff of air in your right eye. If you feel like blinking please do so; just 
let your natural reflexes take over. If you have any questions about what is going to happen you may ask them now.

Participants did not perform any concurrent task during the discrimination and discrimination reversal eyeblink conditioning session. The experimenter was seated in the same room, out of view of the participant to ensure optimal training conditions.

The discrimination and discrimination reversal session consisted of 5 puff alone trials and 120 discrimination and discrimination reversal trials. Puff alone trials were used to determine adequate unconditioned response amplitudes and correct position of the photocell diode. The first 60 trials were discrimination in which the participants received $30 \mathrm{CS}+$ and $30 \mathrm{CS}$ - randomized presentations. A CS + trial was reinforced with a corneal airpuff, the CS- trial was not. Discrimination reversal consisted of 60 trials in which the significance of the tones was reversed. The 30 CS + (previously CS-) and 30 CS- (previously $\mathrm{CS}+$ ) randomized presentations immediately followed the last trial of discrimination with no time lapse except the intertrial interval. Total time to completion of the discrimination and reversal was 25 minutes. Participants were then given postsession interviews in which they were asked to relate what they thought the purpose of the experiment was.

Data AnalysisConditioning trials were collapsed into six blocks of five trials each. The mean percentage of conditioned responses for the control group and the amnesic 
patient group are presented in Table 2. Acquisition of the initial discrimination and subsequent reversal was analyzed with an analysis of variance (ANOVA) examining the between subjects effect of group (control or amnesic patient) and the within subjects effect of tone (CS+ or CS-) and conditioning paradigm percent conditioned responses (discrimination or reversal). Percent conditioned responses was the dependent variable examined. In order to further examine any interactions, separate Condition by Tone, 2way ANOVAs were performed for the initial discrimination and for the discrimination reversal. Comparisons of conditioned response amplitudes and latencies as well as unconditioned response amplitude were made with one-way ANOVAs by group for both discrimination and reversal.

RESULTS

A difference in the pattern of overall performance between the control and amnesic groups based on mean percent conditioned responses was indicated by a significant main effect of Group (Control/Amnesic) by Tone(CS+/CS-) by Conditioning Paradigm (Discrimination/Reversal), $\mathrm{F}(1,14)=10.3, p<.01$. In order to examine the source of this interaction, we performed separate condition Group by Tone, 2-way ANOVAs, for initial discrimination and for discrimination reversal.

Amnesic and control participants were able to successfully discriminate between the CS + and CS- during the initial discrimination period as indicated by a main effect of 
Tone, $F(1,14)=26.9, p<.0001$. The two groups also had similar discrimination performance as indicated by a lack of main effect of Group, $F(1,14)=0.98, p=.339$, and a lack of main interaction between Group by Tone, $F(1,14)=1.21, p=.289$ (Figure 2). It is noticeable in Figure $2 \mathrm{~B}$, however, that the amnesic group did not perform as well as the control group. Further examination of the data indicated that one control participant had an exceptionally large number of conditioned responses to the CS+, almost two standard deviations greater than other control participants. With removal of this participant from the data set, discrimination between CS + and CS- (subtraction of CS- from CS + ) was very similar: Control, $26.6 \pm 7.9(\mathrm{M}$ and SE); Amnesic, $21.7 \pm 4.5$. The differences between groups in Figure 2 appear to be accounted for by one outlier control participant.

Additional pair wise analyses of performance on the initial discrimination revealed that the control group could discriminate between the CS+ and CS-, $t(7)=4.7$, $p<.01$. Similarly, the amnesic group also demonstrated the ability to discriminate between the two tones, $\mathrm{t}(7)=3.5, p=.01$ (Figure 3).

During the discrimination reversal, there was a main effect of Tone, $F(1,14)=71.7$, $p<.0001$, indicating an overall significant discrimination between the tones. No main effect of Group was observed, $F(1,14)=0.45, p>.05$. Critically, however, there was a significant interaction between Group and Tone, $\mathrm{F}(1,14)=48.8, p<.0001$. This reflects the fact that the control group could discriminate between the new CS + and the new 
CS- $, \mathrm{t}(7)=9.7, p<.0001$, whereas the amnesic group could not discriminate between the reversed tones, $\mathrm{t}(7)=1.2, p=.26$ (Figure 3 ).

CR latency and amplitude Table 2 summarized CR latency and amplitude to the CS+ during discrimination and reversal. No differences were observed in the timing and size of the conditioned responses between the two groups for the initial discrimination. CR latency and amplitude were comparable between groups for the $C S+(F(1,14)=4.2, p>$ $.05 ; \mathrm{F}(1,14)=1.2, p>.05)$ and for the $\mathrm{CS}-(\mathrm{F}(1,14)=2.54, p>.05 ; \mathrm{F}(1,14)=0.10$, $p>.05)$

Similarly for the reversal, no differences were observed in the timing and size of the conditioned responses between the two groups. CR latency and amplitude were comparable between the normal control and amnesic groups for both the CS+, $(F(1,14)$ $=1.0, p>.05 ; \mathrm{F}(1,14)=4.1, p>.05)$ and the $\mathrm{CS}-(\mathrm{F}(1,14)=0.04, p>.05 ; \mathrm{F}(1,14)=0.01$, $p>.05)$

Unconditioned response amplitude No differences were observed between groups for unconditioned response amplitude, indicating that the reversal impairment observed in the amnesic patient group was not due to nonassociative sensory motor factors impairing the ability of the amnesic participants to physically perform conditioned responses. Amnesic patients did not differ from controls in the amplitude of the 
unconditioned responses during the initial discrimination $(\mathrm{CS}+, \mathrm{F}(1,14)=1.3 p>.05$;

$\left.\mathrm{CS}_{-}, \mathrm{F}(1,14)=0.7, p>.05\right)$ or during the reversal $\left(\mathrm{CS}+, \mathrm{F}(1,14)=0.1, p>.05 ; \mathrm{CS}_{-}, \mathrm{F}\right.$

$(1,14)=2.6, p>.05)($ Table 2).

Spontaneous blinks and alpha responsesSpontaneous blinks were measured in the 750 ms baseline period before the CS onset on each trial. Amnesic patients $(M=11.6, S E=2.7)$ and control participants $(M=12.3, S E=2.3)$ did not differ in the number of spontaneous blinks during the initial discrimination, $\mathrm{F}(1,14)=0.03, p>.05$. Spontaneous blink activity also did not differ between patients $(M=12.0, S E=1.8)$ and controls $(M=9.4, S E=2.1)$ during reversal, $\mathrm{F}(1,14)=0.9, p>.05$.

Alpha responses or short latency responses occurring during the first $100 \mathrm{~ms}$ of the tone CS were also quantified and compared. Amnesic patients $(M=3.0, S E=1.0)$ and normal control participants $(M=9.1, S E=3.0)$ did not differ in the number of alpha responses during discrimination $(F(1,14)=3.6, p>.05)$ or during reversal (Amnesic $M=$ 4.8, $S E=0.8 ;$ Control $M=4.1, S E=0.9 ; \mathrm{F}(1,14)=0.3, p>.05)$.

Awareness Participants were given post-session interviews in which they were asked to relate what they thought the purpose of the experiment was. Participants were rated as "aware" of the stimulus contingencies if they reported an association between one of the tones and the airpuff, as well as reversal of the significance of the tones. All control 
participants were able to verbalize the relationship between the two tones and the airpuff during discrimination, as well as during reversal. Four amnesic patients were aware of the initial discrimination stimuli contingencies and four were unaware. Two of these four were the only amnesic participants aware of the reversal. The other six remained unaware of the reversal stimulus contingencies, despite the fact that two had claimed awareness of contingencies during discrimination.

We compared performance of the four patients who reported being aware and the four patients who were unaware of the initial discrimination to their matched controls. The aware patients were able to discriminate between two tones as well as controls during the initial discrimination (Amnesic $C S+M=55, S E=9.5 ; C S-M=26.7$, $S E=4.1 ;$ Control $C S+M=55, S E=5.1 ; C S-M=21.7, S E=4.4)$ as evidenced by a lack of main effect of Group, $(F(1,6)=0.13, p=0.7)$ and lack of tone by group interaction $(F(1,6)=0.20, p=0.7)$. This group was not able to reverse the initial discrimination (Amnesic $C S+M=49.2, S E=7.0 ; C S-M=42.5, S E=6.8 ;$ Control $C S+M=55.8, S E=$ 6.9; $C S-M=12.5, S E=2.8)$ as indicated by significant tone by group interaction $(F(1,6)=9.6, p<.05)$. The unaware group was also able to perform the initial discrimination (Amnesic $C S+M=56.7, S E=5.9 ; C S-M=41.7, S E=5.0 ;$ Control $C S+M$ $=60.8, S E=12.1 ; C S-M=26.6, S E=10.2)$, although not as well as the aware group, as evidenced by a lack of main effect $(F(1,6)=0.47, p=0.5)$ and a lack of tone by group interaction $(F(1,6)=0.97, p=0.4)$. Their reversal, however, was impaired (group by 
tone $F(1,6)=114.9, p<.0001$ ) compared to matched controls (Amnesic CS $+M=39.2$, $S E=5.2 ; C S-M=36.7, S E=3.6 ;$ Control $C S+M=70.0, S E=5.1 ; C S-M=17.5, S E=$ 5.3). These results indicate that awareness may not be required to successfully perform a delay discrimination task, however, the sample size for these groups is small and cannot be considered conclusive.

\section{DISCUSSION}

Amnesic patients with damage to medial temporal lobe were able to successfully acquire a two-tone delay discrimination, but were unable to reverse the behavioral significance of the tones. Their reversal conditioning impairment was due to the fact that they are unable to both perform conditioned responses to the new CS+ (old CS-) and to inhibit conditioned responses to the new CS- (old CS+) as well as control participants (Table 2 and Figures 2 and 3). This finding was not due to non-associative sensory motor factors, as there were no differences found between the amnesic and control groups for conditioned response amplitude, latency, or unconditioned responses. In addition, these results are concurrent with medial temporal pathology associated with the patient etiologies and give evidence to a relatively intact cerebellum, a structure that is essential to all classical eyeblink conditioning paradigms (Fortier et al., 2000; Green \& Woodruff-Pak, 2000). Initial acquisition of the delay discrimination conditioning would have been impaired if the cerebellum had been significantly 
damaged in these patients. Thus, it appears that medial temporal lobe damage disrupts the reversal of an acquired two tone delay discrimination in humans.

Spared discrimination and impaired reversal observed in the amnesic group are consistent with reports that hippocampal lesions do not disrupt acquisition of a simple two-tone delay discrimination in rabbits, but do disrupt reversal of the discrimination (Berger \& Orr, 1983; Orr \& Berger, 1985). Orr \& Berger suggested that the hippocampus may not be necessary for the initial encoding of the CS-US contingency for discrimination but that it may be vital for the modification of behavior when environmental constraints change. Although the reversal deficit observed in the present report is not exactly the same as that reported by Orr \& Berger (1985), the present report does extend these findings to human participants.

These findings are also convergent with results from previous human studies of discrimination. Patients with left or right medial temporal lobe resections successfully acquired a simple two-tone delay discrimination (Daum et al., 1992). Clark and Squire (1998) found that amnesic patients were able to acquire a two tone delay discrimination but were impaired in a trace two tone discrimination (consistent with findings that amnesic patients are intact for delay but impaired for trace single-cue conditioning, Gabrieli et al., 1995; McGlinchey-Berroth et al., 1997). Reports of more complex conditioning tasks found that patients with temporal lobe resections were unable to perform a conditional discrimination task, in which the color of a light CS presented 
before a tone signified whether the trial would be reinforced with an airpuff or not, (CSCS-US) (Daum et al., 1989) or its reversal (Daum et al., 1991). Additionally, Myers et al., (2000) reported impaired discrimination and impaired reversal in hypoxic amnesic patients in comparison to their controls in a conditional spatial discrimination task. These results taken together point to the possibility that medial temporal lobe structures, specifically the hippocampus, become essential for the acquisition of increasingly complex conditioning tasks.

The participation of the hippocampus during the acquisition of eyeblink conditioning has been demonstrated repeatedly in conditioning studies of the rabbit nictitating membrane (Berger et al., 1978; Berger et al., 1983; Disterhoft et al., 1986; Schmaltz \& Theios, 1972) and human eyeblink conditioning (Blaxton et al, 1996; Buchel et al., 1999; McGlinchey et al., 1995; McGlinchey et al., 1997). The exact role of this participation is not clear, however, but may be elucidated by the neurocomputational model put forth by Grossberg \& Merrill (1996). In their computational model, Grossberg $\&$ Merrill suggest that hippocampal timing circuits help to maintain attention toward goal objects during variable-task-related delays acquired by the cerebellum. Their adaptive resonance model (ART) suggests that the hippocampus draws attention to salient cues and that together with the cerebellum, cooperates to control adaptively timed recognition learning, motivated attention, and conditioned responding. Their cognitive-emotional model suggests that three types of internal representations interact 
during conditioning: sensory representations that are thalamocortical representations of external events linked to frontal cortex; drive representations that are hypothalamic and amygdala circuits that generate emotional reactions and motivational decisions; and motor representations including cerebellar circuits that control discrete adaptive responses. The authors suggest that these processes then contribute to declarative memory by motivational feedback to the learning and performance of procedural memory. This model accurately accounts for the results observed in the present study. The role of awareness has become a topic of consideration in studies of classical eyeblink conditioning in human participants. Awareness has been addressed in two reports of normal young adults and one comparing younger and older adults. Carrillo, Gabrieli, \& Disterhoft (2000) examined the role of attention in conditioning tasks of varying complexity and found that delay and trace conditioning were unaffected by the level of distraction in young adults, but that conditioning in the two-tone delay paradigms of discrimination and reversal was reduced greatly when attention was divided. Clark \& Squire (1999) found that trace, but not delay, discrimination eyeblink conditioning was a hippocampally dependent task of declarative memory and diminishing awareness with a concurrent visual digit detection task prevented acquisition of trace, but not of delay, discrimination. In contrast to the previous reports, an aging study of awareness found that acquisition of both a delay and trace 
discrimination task was correlated with awareness of conditioning stimulus contingencies, regardless of age (Knuttinen et al., 2001).

Awareness was also recently examined in a group of medial temporal lobe amnesics who were intact for delay but impaired for trace discrimination when performing a concurrent task (watching a silent movie) (Clark \& Squire, 1998). For control participants, successful trace conditioning depended upon awareness of the CSUS contingency (as elicited by a post-task questionnaire), but successful delay conditioning did not depend upon such awareness. Our present findings agree with those of Clark and Squire (1998) that conscious knowledge of stimulus contingencies was not necessary for successful acquisition of delay discrimination eyeblink conditioning. In the present study, a subset of four of the eight amnesic patients who had some declarative knowledge of the task were able to perform the discrimination, equally to a subset of four "unaware" amnesic participants. Neither group was able to make the reversal. This suggests that declarative knowledge is not essential for the acquisition of the delay discrimination, but may be essential for conditioning tasks that require modification of an already learned response set, such as reversal conditioning. In conclusion, patients with medial temporal lobe amnesia were able to successfully acquire a two tone delay discrimination, but were unable to reverse that discrimination. The amnesic patients responded equally to the new CS+ (old CS-), and the new CS- (old CS+). The present study extends findings from previous animal 
reports of discrimination and reversal conditioning to humans (Berger \& Orr, 1985; Orr \& Berger, 1986) as well as human reports of delay discrimination in humans (Daum et al., 1984; Clark \& Squire, 1998; Knuttinen et al., 2001) to the reversal conditioning paradigm. These findings are consistent with the hypothesis that the hippocampus becomes essential when discrimination eyeblink conditioning is reversed. 


\section{REFERENCES}

Akase, E., Alkon, D.L., \& Disterhoft, J.F. (1989). Hippocampal lesions impair memory of short-delay conditioned eyeblink in rabbits. Behavioral Neuroscience, 103, 935-943.

Akase, E., Thompson, L.T., \& Disterhoft, J.F. (1994). A system for quantitative analysis of associative learning. 2. Real-time software for MS-DOS microcomputers. Journal of Neuroscience Methods, 54, 119-130.

Berger, T.W., \& Orr, W.B. (1983). Hippocampectomy selectively disrupts discrimination reversal conditioning of the rabbit nictitating membrane response. Behavioral Brain Research, 8, 49-68.

Berger, T.W., Rinaldi, P.C., Weisz, D.J., \& Thompson, R.F. (1983). Single-unit analysis of different hippocampal cell types during classical conditioning of rabbit nictitating membrane response. Journal of Neurophysiology, 50, 1197-1219.

Berger, T.W., \& Thompson, R.F., (1978). Identification of pyramidal cells as the critical elements in hippocampal neuronal plasticity during learning. Proceedings of the National Academy of Sciences USA, 75, 1572-1576.

Berger, T.W., \& Weisz, D.J. (1987). Single unit analysis of hippocampal pyramidal and granule cells and their role in classical conditioning of the rabbit nictitating membrane response. In W.R. Prokasy \& R.F. Thompson (Eds.), Classical Conditioning (pp. 217-254). Hillsdale, NJ: Erlbaum. 
Blaxton, T.A., Zeffiro, T.A., Gabrieli, J.D.E., Bookheimer, S.Y., Carrillo, M.C., Theodore, W.H., \& Disterhoft, J.F. (1996). Mapping the neuroanatomical correlates of human learning: A PET activation study of eyeblink conditioning. Journal of Neuroscience, 16, 4032-4040.

Buchel, C., Dolan, R.J., Armony, J.L., \& Friston, K.J. (1999). Amygdala-hippocampal involvement in human aversive trace conditioning revealed through even-related functional magnetic resonance imaging. Journal of Neuroscience, 19, 10869-10876.

Carrillo, M.C., Gabrieli, J.D.E., \& Disterhoft, J.F. (2000). Selective effects of division of attention upon discrimination conditioning. Psychobiology, 28, 293-302.

Carrillo, M.C., Thompson, L.T., Gabrieli, J.D.E., \& Disterhoft, (1997). Variation of the intertrial interval in human classical conditioning. Psychobiology, 25, 152-157.

Clark, G.A., McCormick, D.A., Lavond, D.G., \& Thompson, R.F. (1984). Effects of lesions of cerebellar nuclei on conditioned behavioral and hippocampal neuronal responses. Brain Research, 291, 125-136.

Clark, R.E., \& Squire, L.R. (1998). Classical conditioning and brain systems: The role of awareness. Science, 280, 77-81.

Clark, R.E., \& Squire, L.R. (1999). Human eyeblink classical conditioning: Effects of manipulating awareness of the stimulus contingencies. Psychological Science, 10, 1418. 
Daum, I., Channon, S., \& Canavan, A.G.M. (1989). Classical conditioning in patients with severe memory problems. Journal of Neurology, Neurosurgery and Psychiatry, 52, 47-51.

Daum, I., Channon, S., \& Gray, J.A. (1992). Classical conditioning after temporal lesions in man: Sparing of simple discrimintion and extinction. Behavioral Brain Research, 52, 159-165.

Daum, I., Channon, S., Polkey, C.E., \& Gray, J.A. (1991). Classical conditioning after temporal lesions in man: Impairment in conditional discrimination. Behavioral Neuroscience, $105,396-408$.

Daum, I., Schugens, M.M., Ackermann, H., Lutzenberger, W., Dichgans, J., \& Birbaumer, N. (1993). Classical conditioning after cerebellar lesions in humans. Behavioral Neuroscience, 107, 748-756.

Disterhoft, J.F., Coulter, D.A., \& Alkon, D.L. (1986). Conditioning-specific membrane changes of rabbit hippocampal neurons measured in vitro. Proceeding of the National Academy of Sciences USA, 83, 2733-2737.

Fortier, C.B., Disterhoft, J.F., \& McGlinchey-Berroth, R. (2000). Cerebellar cortical degeneration disrupts discrimination learning but not delay or trace classical eyeblink conditioning. Neuropsychology, 14, 537-50. 
Gabrieli, J.D.E, McGlinchey-Berroth, R., Carrillo, M.C., Gluck, M.A., Cermak, L.S., \& Disterhoft, J.F. (1995). Intact delay-eyeblink conditioning in amnesia. Behavioral Neuroscience, 109, 819-827.

Gormezano, I. (1966). Experimental methods and instrumentation in psychology. In J. B. Sidowski (Ed.), Classical Conditioning (pp. 385-420). New York: McGraw-Hill. Gormezano, I., Kehoe, E.J., \& Marshall, B.S. (1983). Twenty years of classical conditioning research with the rabbit. Progress in Psychobiology and Physiological Psychology, 10, 197-275.

Green, J.T., \& Woodruff-Pak, D.S. (2000). Eyeblink classical conditioning: Hippocampal formation is for neutral stimulus associations as cerebellum is for association-response. Psychological Bulletin, 126, 138-158.

Grossberg, S., \& Merrill, J.W.L. (1996). The hippocampus and cerebellum in adaptively timed learning, recognition, and movement. Journal of Cognitive Neuroscience, 8, 257-277.

Kesner, R.P. \& Hopkins, R.O. (2001). Short-term memory for duration and distance in humans: Role of the hippocampus. Neuropsychology, 15, 58-68.

Knuttinen, M.G., Power, J.M., Preston, A.R., \& Disterhoft, J.F., (2001). Awareness in classical differential eyeblink conditioning in young and aging humans. Behavioral Neuroscience, (in press). 
Lavond, D.G., Hembree, T.L., \& Thompson, R.F. (1985). Effect of kianic acid lesions of the cerebellar interpositus nucleus on eyelid conditioning in the rabbit. Brain Research, 326, 179-182.

Lavond, D.G., Lincoln, J.C., McCormick, D.A., \& Thompson, R.F. (1984). Effect of bilateral lesions of the dentate and interpositus cerebellar nuclei on conditioning of heart rate and nictitating membrane eyelid responses in the rabbit. Brain Research, 305, 323-330.

Lincoln, J.D., McCormick, D.A., \& Thompson, R.F. (1982). Ipsilateral cerebellar lesions prevent learning of the classically conditioned nictitating membrane/eyelid response. Brain Research, 242, 190-193.

Logan, C.G., \& Grafton, S.T. (1995). Functional anatomy of human eyeblink conditioning determined with regional cerebral glucose metabolism and positron emission tomography. Proceedings of the National Academy of Sciences USA, 92, 7500-7504.

Lye, R.H., O'Boyle, D.J., Ramsden, R.T., \& Schady, W., (1988). Effects of a unilateral cerebellar lesion in the acquisition of eye-blink conditioning in man. Journal of Physiology, 403, 58.

Manns, J.R., Clark, R.E., \& Squire, L.R. (2000). Awareness predicts the magnitude of single-cue trace eyeblink conditioning. Hippocampus, 10, 181-6. 
McCormick, D.A., \& Thompson, R.F. (1984a). Cerebellum: Essential involvement in the classically conditioned nictitating eyelid response. Science, 223, 296-299.

McCormick, D.A., \& Thompson, R.F. (1984b). Neuronal responses of the rabbit cerebellum during acquisition and performance of a classically conditioned nictitating membrane-eyelid response. Journal of Neuroscience, 4, 2811.

McEchron, M., \& Disterhoft, J.F. (1997). Sequence of single neuron changes in CA1 hippocampus of rabbits during acquisition of trace eyeblink conditioned responses. Journal of Neurophysiology, 78, 1030-1044.

McEchron, M., \& Disterhoft, J.F. (1999). Hippocampal encoding of nonspatial trace conditioning. Hippocampus, 9, 385-396.

McGlinchey-Berroth, R., Brawn, C., \& Disterhoft, J.F., (1999). Temporal discrimination learning in severe amnesic patients reveals an alteration in the timing of eyeblink conditioning responses. Behavioral Neuroscience, 113, 10-18.

McGlinchey-Berroth, R., Carrillo, M.C., Brawn C.M., Gabrieli, J.D.E., Cermak, L.S., \& Disterhoft, J.F. (1997). Impaired trace eyeblink conditioning in medial temporal lobe amnesia. Behavioral Neuroscience, 111, 873-882.

McGlinchey-Berroth, R., Cermak, L.S., Carrillo, M.C., Armfield, S., Gabrieli, J.D.E., \& Disterhoft, J.F. (1995). Impaired delay eyeblink conditioning in amnesic Korsakoff's patients and recovered alcoholics. Alcoholism: Clinical and Experimental Research, 19, $1127-1132$. 
Miller, D.P., \& Steinmetz, J.E. (1997). Hippocampal activity during classical discrimination-reversal eyeblink conditioning in rabbits. Behavioral Neuroscience, 111, 70-79.

Moyer, J.R., Deyo, R.A., \& Disterhoft, J.F. (1990). Hippocampectomy disrupts trace eye-blink conditioning in rabbits. Behavioral Neuroscience, 104, 242-252.

Myers, C.E., Hopkins, R.O., Kesner, R.P., Monti, L., \& Gluck, M.A. (2000). Impaired acquisition, and altered reversal, on a conditioned spatial discrimination in humans with hypoxic brain injury. Psychobiology, 28(3), 275-282.

Orr, W.B. \& Berger, T.W. (1985). Hippocampectomy disrupts the topography of conditioned nictitating membrane responses during reversal learning. Behavioral Neuroscience, 99, 35-45.

Schmaltz, L.W., \& Theios, J. (1972). Acquisition and extinction of a classically conditioned response in hippocampectomized rabbits (Oryctolagus cuniculus). Journal of Comparative and Physiological Psychology, 79, 328-333.

Solomon, P.R, \& Moore, J. (1975). Latent inhibition and stimulus generalization of the classically conditioned nictitating membrane response in rabbits (Oryctolagus cuniculus) following dorsal hippocampal ablation. Journal of Comparative and Physiological Psychology, 89, 1192-1203. 
Solomon, P.R., Stowe, G.T., \& Pendlebury, W.P. (1989). Disrupted eyelid conditioning in a patient with damage to the cerebellar afferents. Behavioral Neuroscience, 103, 898-902.

Solomon, P.R., Vander Schaaf, E., Thompson, R.F., \& Weisz, D.J. (1986). Hippocampus and trace conditioning of the rabbit's classically conditioned nictitating membrane response. Behavioral Neuroscience, 100, 729-744.

Thompson, R.F. (1986). The neurobiology of learning and memory. Science, 233, 941-947.

Thompson, R.F. (1988). The neural basis of basic associative learning of discrete behavioral responses. Trends in Neurosciences, 11, 152-155.

Thompson, L.T., Moyer, J.R., Akase, E., \& Disterhoft, J.F. (1994). A system for quantitative analysis of associative learning. 1. Hardware interfaces with cross-species applications. Journal of Neuroscience Methods, 54, 109-117.

Topka, H., Valls-Sole, J., Massaquoi, S.G., \& Hallet, M. (1992). Deficit in classical conditioning in patients with cerebellar degeneration. Brain, 116, 961-969.

Verfaellie, M., Koseff, P., \& Alexander, M.P. (2000). Acquisition of novel semantic information in amnesia: Effects of lesion location. Neuropsychologia, 38, 484-492.

Wechsler, D. (1981). Wechsler Adult Intelligence Scale-Revised (manual). New York: Psychological Corporation. 
Wechsler, D. (1987). Wechsler Memory Scale-Revised (manual). New York:

Psychological Corporation.

Weiss, C., Bouwmeester, H., Power, J.M. and Disterhoft, J.F. (1999). Hippocampal lesions prevent trace eyeblink conditioning in the freely moving rat. Behavioral Brain Research, 99, 123-132.

Weiss, C., Kronforst-Collins, M.A., \& Disterhoft, J.F. (1996). Activity of hippocampal pyramidal neurons during trace eyeblink conditioning. Hippocampus, 6 , 192-209.

Woodruff-Pak, D.S., Papka, M., \& Ivry, R.B. (1996). Cerebellar involvement in eyeblink classical conditioning in humans. Neuropsychology, 10, 443-458.

Yeo, C.H., Hardiman, M.J., \& Glickstein, M. (1985). Classical conditioning of the nictitating membrane response of the rabbit: I. Lesions of the cerebellar nuclei. Experimental Brain Research, 60, 87-98. 